\title{
Dos sonhos criativos a realidade em movimento: Relações entre a Análise Textual Discursiva e o Pensamento Complexo
}

\author{
I De los sueños creativos la realidad en movimiento: Relaciones entre el \\ Análisis textual Discursivo y el Pensamiento Complejo
}

\author{
I From Creative Dreams to Reality in Motion: Relationships between \\ Discursive Textual Analysis and Complex Thought
}

\author{
Rafaele Rodrigues de Araujo ${ }^{1}$ \\ Valmir Heckler ${ }^{2}$
}

\begin{abstract}
Resumo
O presente trabalho tem por objetivo descrever o caminho metodológico utilizado para investigar e compreender a formação inicial interdisciplinar em curso de licenciatura em Ciências da Natureza. Para isso, realizamos uma articulação entre a metodologia de pesquisa da Análise Textual Discursiva (ATD) de Moraes e Galiazzi e os princípios epistemológicos do Pensamento Complexo de Edgar Morin. A ATD apresenta um caráter fenomenológico-hermenêutico que possibilita a produção de compreensões sobre fenômenos e discursos, os quais foram significados pelo símbolo do filtro dos sonhos, inspirador da criatividade, da imaginação e que ajuda a transformar e materializar os sonhos e objetivos pretendidos, orientados pelos princípios do pensamento complexo. Assim, explicitamos que as compreensões geradas pelo ciclo da ATD, no processo de desconstruir, reconstruir e comunicar as emergências da análise realizada estão articuladas com o circuito tetralógico (desordem/interações/ordem/organização) de Morin, o qual é orientado pela dialógica, a recursividade e o hologramático, evidenciado a indissociabilidade entre os aspectos metodológicos e epistemológicos da pesquisa. Concluímos que com o filtro dos sonhos transformado, temos no primeiro movimento a desconstrução e a desordem. Ordem e organização se desenvolvem nesse processo de interações com interlocuções com teóricos e informações empíricas do qual emergem as categorias de uma análise qualitativa, pautada na significação e na compreensão dos pesquisadores. E, por fim, a comunicação das novas compreensões ocorre por intermédio das emergências, o qual advêm com os argumentos expressos pela linguagem.
\end{abstract}

Palavras-Chave: Análise Textual Discursiva; Educação em Ciências; Interdisciplinaridade; Metodologia Qualitativa; Pensamento Complexo.

\section{Resumen}

O presente trabajo por objetivo o por medio de un método metodológico utilizado para investigar y comprender una forma inicial interdisciplinaria en el curso de licenciatura en Ciencias de la Naturaleza. Para ello, realizamos una articulación entre una metodología de pesquería de análisica Textual Discursiva (ATD) de Moraes y Galiazzi y los principios epistemológicos de Pensamento Complexo de Edgar Morin. A ATD Apresenta um Carenter fenomenológico-hermenêutico que possibilita un produção de compreensões sobre fenômenos and discursos, os quais foram significados el símbolo del filtro de sonido, inspirador da criativitye, da imaginação e ajuda un material y unos e e ehos e adsumirantes, orientados Pelos princípios de pensamiento complejo. Asignar, explícitamente como compilaciones, ciclo de vida de ATD, sin proceso de desconcierto, reconstruir y comunicar como emergencias en la posición de las articulaciones con el circuito tetralógico (desordem / interações / ordem / organização) de Morin, o qual é orientado pela dialógica, una recursividad eo hologramático, evidenciado una indisociabilidad entre los aspectos metodológicos y epistemológicos da pesquisa. Conclusiones del filtro de sonido transformado, sin embargo, no se ha producido ningún cambio en el orden y el desorden. La organización y el desarrollo se procesan con intercomunicaciones con intercomunicaciones con información teórica e

\footnotetext{
${ }^{1}$ Doutora em Educação em Ciências; Universidade Federal do Rio Grande - FURG; Rio Grande, Rio Grande do Sul, Brasil; rafaelearaujo@furg.br.

${ }^{2}$ Doutor em Educação em Ciências; Universidade Federal do Rio Grande - FURG; Rio Grande, Rio Grande do Sul, Brasil; valmirheckler@furg.br.
} 
información acerca de las características de las empresas cualitativas, pautada en el sentido y compaginación. E, por fim, una comunicação das novas compreensões ocorre por intermédio das emergências, o la calidad de los argumentos expresos en la lengua.

Palabras claves: Análisis textual Discursivo; Educación en Ciencias; interdisciplinariedad; Metodología Cualitativa; Pensamiento Complejo.

\begin{abstract}
The aim this present work is describes the methodological pathway used to investigate and understand the initial interdisciplinary formation in the Nature Sciences. For this, we articulate the research methodology of Discursive Textual Analysis (ATD) by Moraes and Galiazzi and the epistemological principles of Edgar Morin's Complex Thought. The ATD has a phenomenological-hermeneutic character that enables the production of understandings about phenomena and discourses, that were signified by the dream filter symbol, inspiring creativity and imagination that helps to transform and materialize the dreams and goals intended, guided by the principles of complex thought. Thus, we explain that the understandings generated by the ATD cycle, in the process of deconstructing, reconstructing and communicating the emergencies of the analysis performed, are articulated with the Morin's tetralogical circuit (disorder / interactions / order / organization), which is guided by the dialogic, recursive and hologramatic, evidenced by the indissociability between the methodological and epistemological aspects of the research. We conclude that, with the dream filter transformed, we have in the first movement the deconstruction and the disorder. Order and organization develop in this process of interactions from which the categories emerge. And, finally, the communication of the new understandings occurs through the emergencies, which come with the arguments expressed by language.
\end{abstract}

Keywords: Discursive Textual Analysis; Education in Sciences; Interdisciplinarity; Qualitative Methodology; Complex Thought.

\title{
1. Introdução
}

O estudo abrange a interlocução teórica e exemplifica o caminho metodológico utilizado para investigar e compreender a formação inicial interdisciplinar em Ciências da Natureza, desenvolvida ao longo de um doutoramento (ARAÚJO, 2017). Para isso, ao longo do mesmo problematizamos o sonho e a realidade como metáfora criativa e criadora das compreensões e regenerações que vamos produzindo. A metáfora “(...) dispõe de virtudes quase sempre desconhecidas: é um 'indicador de uma não linearidade, de uma abertura do texto ou do pensamento para diversas interpretações, por ecoar nas ideias pessoais de um leitor ou de seu interlocutor'”. (MORIN, 2012, p. 99, grifo do autor). Logo, a escrita do texto transita entre o pensamento mítico (muthos) e o pensamento racional (logos) que integram nossa condição humana.

As relações que fazemos entre o pensamento mítico e racional, fazem com que ampliamos nossas compreensões e significados, pois “(...) o pensamento racional tornará a imagem da realidade para captar a realidade na imagem; o pensamento mitológico pega a realidade da imagem para alimentar o mundo imaginário" (idem, p. 105). Assim, pensamentos racionais e mitológicos opõem-se da mesma forma que se complementam. Registramos que o imaginário e o simbólico nos ajudam a compreender e produzir a realidade. 
Nessa perspectiva, o estudo intenciona assumir-se dialógica, pois somos constituídos por essa dualidade de pensamentos, através dos símbolos e significados que nos levam a investigação da pesquisa.

Chegamos talvez ao ponto e ao momento de fazer dialogar nossos mitos com as nossas dúvidas, nossas dúvidas com nossos mitos. Temos uma necessidade imperiosa da correção empírica/lógica/racional de todas as nossas atividades mentais, mas necessitamos também da cobertura imaginária/simbólica que ajuda a tecer a realidade e constrói os mitos: "We are such stuff as dreams are made". O pensamento racional necessita de seu duplo. (MORIN, 2015a, p.194, grifo do autor)

Com esse pensamento, distinguiremos e uniremos sonhos e realidade, de distintas pessoas, sejam dos autores, interlocutores teóricos, na interação com a cultura, com o outro, com as memórias e as lógicas que mobilizamos para aprender e compreender. O sonho é produtor de símbolos, inconscientemente e espontaneamente (JUNG, 2008). Esses símbolos, que partem dos nossos sonhos, mesmo sendo expressões do inconsciente remetem a relação da própria realidade e da realidade designada (MORIN, 2015a). Nessa perspectiva, a pesquisa é vista como um sonho, que produz símbolos, mostrando significados no decorrer da pesquisa que não são imediatos e nem óbvios, carregando uma noção identitária que não depende apenas das regras formais da lógica, pois possui uma implicação hologramática e uma função comunitária.

Buscamos através dessa investigação compreender uma realidade conhecida e, ao mesmo tempo, desconhecida, assim como são nossos sonhos que, muitas vezes, tememos ao tê-los. Na compreensão do sonho como produtor de símbolos, “(...) vamos interpretá-lo de maneira diferente daquele que acredita que a emoção e o pensamento energético já são conhecidos e estão apenas “disfarçados" pelo sonho" (JUNG, 2008, p. 65, grifo do autor).

A realidade é ontológica, depende da construção humana realizada pelo sujeito, ou seja, cada sujeito constrói sua realidade. Essa é “(...) uma construção que é certamente sempre incerta, porque o sujeito encontra-se inserido na realidade que pretende conhecer". (MORIN, CIURANA e MOTTA, 2003, p. 37). Sonho e realidade são diferentes e opostos, “(...) partem dois mundos antagônicos e complementares (...), se alimentam um do outro; mais ainda sempre há algo de um no outro”. (MORIN, 2015a, p. 124). Nessa perspectiva, ressaltamos que “(...) o tecido da vida é feito também de sonhos, como o dos sonhos é feito de vida. A composição e a dose variam. Da mesma forma que necessita de afetividade, a realidade necessita do imaginário para ganhar consistência”. (MORIN, 2012, p. 132).

Os sonhos são modos de expressão do nosso inconsciente, altamente simbólicos, e os comunicamos e compartilhamos com outras pessoas por meio da linguagem. Como explicita Morin (2015a, p. 171), “(...) o espírito humano mora na linguagem, vive de linguagem e 
alimenta-se de representações". Assim, nesse estudo, compartilharemos nosso sonho com os interlocutores teóricos, por meio da metodologia de pesquisa da Análise Textual Discursiva (ATD) de Moraes e Galiazzi e os princípios epistemológicos do Pensamento Complexo de Edgar Morin, dividindo nossos processos e compreensões por meio da linguagem escrita.

\section{Pensamento Complexo: a metáfora do sonho}

O pensamento complexo se constitui por um tecido de “(...) constituintes heterogêneas inseparavelmente associadas” que podem ser de “(...) acontecimentos, ações, interações, retroações, determinações, acasos, que constituem nosso mundo fenomênico". (MORIN, 2015b, p.13). O RE complexo nos mostra as relações com a metáfora do sonho através da recorrência dentro do próprio pensamento complexo. Assim, explicitamos na figura 1 suas relações com os princípios que o embasam e o nosso sonho decorrente e estruturante desse estudo.

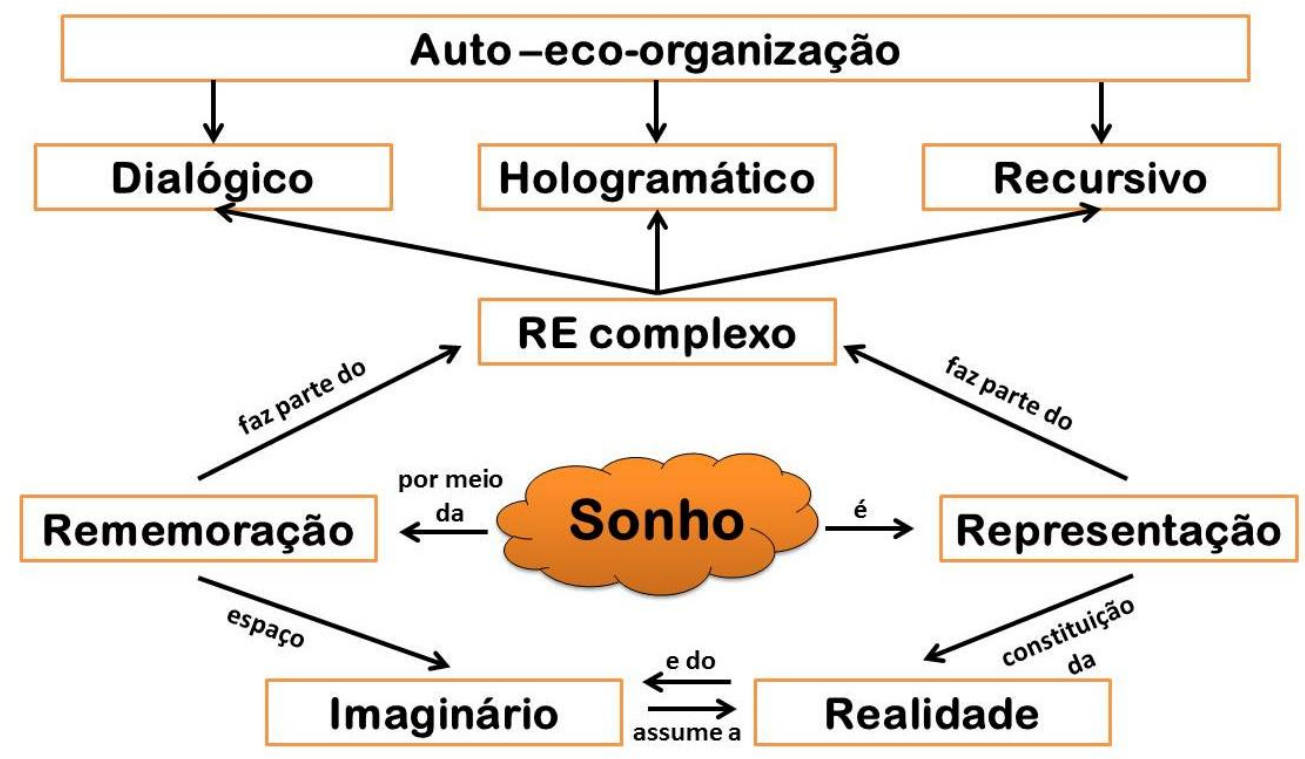

Figura 1: Representação do sonho a partir da complexidade

Fonte: os autores

Compreendemos com o mapa conceitual, exposto na figura 1, que o RE complexo, o qual elencamos para a discussão, tem intrínseco os três princípios que ajudam a pensar na complexidade e suas conexões com o sonho. Para isso, dialogaremos sobre esses conceitos apresentados no mapa conceitual ao longo dessa escrita, no entanto iniciaremos a partir do sonho. 
O que é o sonho? Sonho é uma representação, que nos remete a diversos símbolos, os quais produzimos separando e liberando de nossas percepções. Sendo que nossas percepções e conhecimentos, ideais ou teóricos, são considerados uma tradução e uma reconstrução das informações (MORIN, 2012). Os sonhos se desenvolvem no ato de rememoração em um espaço imaginário que assume a realidade. E esse processo de rememoração “(...) opera a representação global de um fenômeno ou de uma situação". (MORIN, 2015a, p. 116). Nesse entendimento, ressaltamos que:

Tudo passa pela representação: trata-se da encruzilhada entre passado e presente, entre vigília e sonho. Assim, ainda que a percepção do real se oponha às visões imaginárias, a representação é o ato constitutivo idêntico e radical do real e do imaginário. (MORIN, 2015a, p. 123, grifo do autor)

A representação, na perspectiva do pensamento complexo, pode ser entendida como “(...) um reflexo quase ótico da realidade percebida” pelo sujeito (MORIN, 2015a, p. 121). E a representação e rememoração fazem parte da ideia de auto-eco-organização, inerente ao prefixo RE, o qual em uma organização viva, amplia essa relação no seu próprio circuito, ou seja, o RE complexo é auto(geno-feno-ego)ecorre(retro-meta)organizador. O sistema autoeco-organizador temos uma autonomia e individualidade que são dependentes do meio ambiente e das trocas externas que fazemos. Dessa forma, temos uma autonomia dependente. (MORIN, 2012; 2015c).

O RE complexo no sistema auto(geno-feno-ego)ecorre(retro-meta)organizador, primeiramente está no "(...) interior do indissociável paradigma da organização biológica" (MORIN, 2015a, p. 387). O conjunto geno-feno-ego temos a autonomia da auto-organização viva “(...) do generativo em relação ao fenomênico e do fenomênico em relação ao generativo, dependência mútua que constrói a autonomia do todo e, por isso, de ambos" (idem, p. 145). $\mathrm{Na}$ auto(geno-feno-ego)organização somos dependentes “(...) de uma inscrição genética, de informações que emanam dos acontecimentos interiores e exteriores, da atividade total do seraparelho, da auto(geno-feno)ecorreorganização" (idem, p.215), dentro desse circuito permanentemente retro e meta.

Dentro dessa compreensão, o prefixo RE apresenta uma ramificação de conceitos a medida que as ações se tornam diversificadas. Esse condiz com o princípio dialógico, visto que é uno sendo plural/diverso/múltiplo. No princípio dialógico, temos que para a existência, funcionamento e desenvolvimento de um fenômeno é necessário a associação complexa em conjunto de complementaridade/concorrência/antagonia. Assim, temos conceitos que "(...) são complementares, mas também antagônicos" (MORIN, 2015b, p. 73). Os acontecimentos 
não ocorrem dentro de uma só lógica, nesse sentido temos que transcender esse pensamento mutilador e olhar a partir da multidimensionalidade, com um pensamento dialógico.

Na compreensão do nosso RE complexo, afirmamos que esse é total e global, pois envolve outros fenômenos e tem relação com a vida em seu conjunto. No entanto, não podemos ver só as partes e nem só o todo, pois “(...) o todo está de certa maneira incluído (gravado) na parte que está incluída no todo”. (MORIN, 2015a, p. 114). Para compreendermos o princípio hologramático não adianta sabermos que existem as relações entre partes/todo e uno/diverso, mas entender a complexidade que existe nessas associações. Dessa forma, essas vão além, sendo que:

\footnotetext{
- O todo é mais do que a soma das partes (...), visto que em seu nível surgem não só uma macrounidade, mas também emergências, que são qualidade/propriedades novas.

- O todo é menos do que a soma das partes (porque elas, sob efeito das coações resultantes da organização do todo, perdem ou vêem inibirem-se algumas das suas qualidades ou propriedades).

- $O$ todo é mais do que o todo, porque o todo enquanto todo retroage sobre as partes, que por sua vez, retroagem sobre o todo (...). (MORIN, 2014, p. 261-262, grifos do autor).
}

E, assim como, para compreender o pensamento complexo, dependemos desse circuito recursivo, o qual o todo que está contido nas partes que estão contidas no todo. "A ideia de circuito recursivo (...) trata-se de uma ideia primordial para conceber a autoprodução e a autoorganização" (MORIN, 2015a, p.113), pois reforça a conceito de totalidade ativa, ou seja, “(...) o processo em sua totalidade que é generativo desde que ele efetive um circuito sobre si mesmo” (MORIN, 2016, p. 230). Assim, nosso RE complexo “(...) já não é mais concebido como mecânica repetitiva; ele aparece simultaneamente como coprodutor e coproduzido de tudo aquilo que vive" (MORIN, 2015c, p. 380).

\section{Análise Textual Discursiva: as compreensões do sonho}

A Análise Textual Discursiva (ATD) apresenta um caráter hermenêutico-fenomenológico, possibilitando a produção de compreensões sobre fenômenos e discursos (MORAES e GALIAZZI, 2007). Por meio da ATD iniciou-se um movimento para dar sentidos aos nossos sonhos criadores e criativos, com um intuito de comunicar compreensões de uma realidade que se encontra em movimento e de possibilidades que emergem do nosso caminho metodológico.

Ao longo desse processo, como afirmam Moraes e Galiazzi (2007, p. 43), “(...) é preciso estar atento para captar o emergente e registrar as impressões que carrega. Tal como um 
sonho, essas inspirações criativas tendem a ser esquecidas se não forem registradas imediatamente". Nesse sentido, ao trabalharmos com a ATD, lidamos com a construção de significados registrados a partir de um conjunto de textos, sendo esses intitulados de "corpus"3 da pesquisa. Por intermédio desse "corpus", vivenciamos um ciclo auto-organizado, de movimentos de desconstrução, reconstrução e comunicação, permeados pela ordem, desordem e caos, movimentos envolvidos na percepção das emergências do fenômeno que investigamos.

Assumimos nossa pesquisa como qualitativa, de abordagem hermenêuticafenomenológica, articulada aos princípios do pensamento complexo. O fenômeno é o que notamos na intuição ou na percepção, como ressalta Bicudo (2011, p.30):

(...) a Fenomenologia está dizendo que não se trata de um objeto objetivamente
posto e dado pelo mundo exterior ao sujeito e que pode ser observado, manipulado,
experimentado, medido, contado por um sujeito observador. (...) fenômeno é o que
se mostra no ato de intuição, efetuado por um sujeito individualmente
contextualizado, que olha em direção ao que se mostra de modo atento (...).

A fenomenologia tem por finalidade trabalhar o sentido de um contexto para o sujeito, por meio do que se mostra e manifesta para esse. A fenomenologia vai além de uma visão objetivista de compreensão do objeto. Dessa forma, sujeito e objeto, na perspectiva da complexidade, compõem-se nesse processo. "Pesquisa, hoje, implica co-construção, coprodução e co-criação do conhecimento científico como decorrência do diálogo fundamental entre sujeito e objeto do conhecimento" (MORAES e LA TORRE, 2006, p.151). Precisamos superar a visão cartesiana em que sujeito e objeto são ruídos um do outro, e de acordo com Morin (2015a, p.31) “(...) encarar o problema complexo em que o sujeito cognoscente, permanecendo sujeito, torna-se objeto do seu conhecimento". Assim, nessa perspectiva, sujeito e objeto se complementam, incorporando e assumindo os elementos da subjetividade e da objetividade na construção do conhecimento.

Sendo assim, compreendemos que a intersubjetividade também faz parte como pressuposto epistemológico do paradigma da ciência contemporânea, que considera a interdependência entre observador, observação e objeto observável (VASCONCELLOS, 2013; MORAES e LA TORRE, 2006). A intersubjetividade ocorre, como explicita Vasconcellos (2013, p. 151, grifo do autor) quando “(...) ao reconhecer sua própria participação na constituição da "realidade" com que está trabalhando, e ao validar as possíveis

\footnotetext{
${ }^{3}$ De acordo com Moraes e Galiazzi (2007) a denominação foi retirada de Laurence Bardin (1977). O autor define corpus como um "(...) conjunto de documentos tidos em conta para serem submetidos aos procedimentos analíticos” (BARDIN, 2011, p. 126).
} 
realidades instaladas por distinções diferentes, o observador se inclui de forma autêntica no sistema que o distingui (...)". Consideramos que essas realidades diversas, na intersubjetividade, são advindas do reconhecimento do outro, através das suas experiências, compreensões e interpretações.

Além disso, compreendemos que a intersubjetividade acontece, conforme afirmam Bicudo e Klüber (2013, p.30, grifo do autor), no momento em que a “(...) subjetividade se transcende por ser constituída no estar-com-o-outro, a quem ela sempre se abre na visada intencional pelos atos perceptivos e empáticos ao dirigir-se para o que está à sua volta". Assim, adentramos na análise das informações produzidas, por meio da cocriação, visto que nesse estar-com-o-outro, pesquisador e sujeitos de pesquisa se tornaram constituintes do processo. Etapa em que “(...) requer que o pesquisador procure superar uma descrição estática para conseguir captar a realidade em movimento" (MORAES e GALIAZZI, 2007, p. 40).

Ao discorrermos sobre a realidade, a partir do pensamento complexo, retornamos a questão da complementaridade entre sujeito e objeto, da reintrodução do sujeito cognoscente no conhecimento, como afirma Edgar Morin. De acordo com o autor, "o sujeito não reflete a realidade. O sujeito constrói a realidade por meio dos princípios (...)" (MORIN, CIURANA e MOTTA, 2003, p. 37). O autor refere-se a sete princípios organizadores do pensamento complexo: Princípio sistêmico, hologramático, retroativo, recursivo, autonomia/dependência, dialógico e reintrodução do sujeito cognoscente em todo conhecimento.

Dessa forma, a construção da realidade ocorre religando o conhecimento das partes com o conhecimento do todo e vice-versa, o qual os efeitos ou produtos são causas e produtos do próprio processo, com lógicas que se complementam e se excluem. A realidade construída é auto-eco-organizada e “(...) é certamente sempre incerta, porque o sujeito encontra-se inserido na realidade que pretende conhecer" (ibidem, p.37).

Nesse sentido, registramos que a realidade é ontológica, sujeita a construção humana. Essa construção é influenciada pela realidade objetiva e subjetiva, em que o curso está inserido, da pesquisadora e pelas experiências dos sujeitos de pesquisa. Fernando Pessoa, na obra Livro do Desassossego, ressalta a realidade como construção nossa, do sujeito em suas interações.

Damos comumente às nossas ideias do desconhecido a cor das nossas noções do conhecido: se chamamos à morte um sono é porque parece um sono por fora; se chamamos à morte uma nova vida é porque parece uma coisa diferente da vida. Com pequenos mal-entendidos com a realidade construímos as crenças e as esperanças, e vivemos das côdeas a que chamamos bolos, como as crianças pobres que brincam a ser felizes. Mas assim é toda a vida; assim, pelo menos, é aquele sistema de vida particular a que no geral se chama civilização. A civilização consiste em dar a qualquer coisa um nome que lhe não compete, e depois sonhar sobre o resultado. $\mathrm{E}$ realmente o nome falso e o sonho verdadeiro criam uma nova realidade. $\mathrm{O}$ objeto torna-se realmente outro, porque o tornámos outro. (PESSOA, 2013, p. 66). 
Registramos que a realidade é complexa e para Ilya Prigogine (1996) está profundamente ligada com o tempo, como matéria-prima criadora da mesma, sendo que ao desprezarmos o tempo, negamos a realidade, e ao negá-la renunciamos o possível, o futuro (CARVALHO, 2012; PRIGOGINE, 2003). “O tempo e a realidade estão irredutivelmente ligados. Negar o tempo pode parecer um consolo ou aparecer como triunfo da razão humana, é sempre uma negação da realidade" (PRIGOGINE, 1996, p. 197). O tempo é uma construção, assim como a realidade, a qual nessa investigação partimos dos símbolos emergentes do sonho, seja na organização curricular do curso, na perspectiva dos sujeitos de pesquisa e até mesmo na vivência da pesquisadora.

Nesse sentido, “(...) enquanto humanos, temos vislumbres de fragmentos da realidade (...)" (CARVALHO, 2012, p. 57), a qual demanda um pensamento multidimensional, que faz parte de uma conexão entre pensamento, linguagem e realidade (MORAES, 2012; MORIN, CIURANA e MOTTA, 2003). Vasconcellos (2013, p. 132) ressalta que “(...) a linguagem constitui a realidade, ou seja, que por meio da linguagem são vistas as coisas". Nessa multidimensionalidade, a linguagem permeia a simplificação e a complexidade constituindo nosso pensamento.

A linguagem traduz e transfere em enunciados lineares/sequenciais o que se manifesta como simultaneidade superposta no cérebro e no real. (...) Assim, a linguagem é uma simplificação complexificadora que permite utilizar uma parte da hipercomplexidade cerebral, construir/reconstruir uma nova complexidade discursiva e assim dialogar com a complexidade do real. (MORIN, 2015a, p. 134135)

E por intermédio da linguagem, ao coconstruirmos as informações em conjunto com os sujeitos que fazem parte da pesquisa, que nossa análise se caracteriza dentro de uma abordagem fenomenológica e hermenêutica. Schmidt (2014, p. 23) afirma que “(...) a hermenêutica, de uma forma ou outra, persistirá enquanto os seres humanos usarem a linguagem para se comunicarem uns com os outros”. Assim, com as informações produzidas pela linguagem e com nossos pensamentos, uma dialógica do abstrato/concreto/vivido (MORIN, 2015a). Esse movimento, em direção à compreensão das realidades desse estudo, será conduzido por meio da ATD, visto que essa

(...) tem fundamentos na fenomenologia e na hermenêutica. Valoriza os sujeitos em seus modos de expressão dos fenômenos. Centra sua procura em redes coletivas de significados construídos subjetivamente, os quais o pesquisador se desafia a compreender, descrever e interpretar. São processos hermenêuticos. (MORAES e GALIAZZI, 2007, p. 169). 
Com isso, nosso próximo movimento do estudo será em realizar as articulações entre a Análise Textual Discursiva e o Pensamento Complexo, de modo que explicitaremos essas relações a partir do símbolo do filtro dos sonhos.

\section{Análise Textual Discursiva e o Pensamento Complexo: o movimento do Filtro dos} Sonhos

Dialogamos nesse tópico do estudo com os processos metodológicos da Análise Textual Discursiva e com a teoria do Pensamento Complexo, na qual ambas se unem e se complementam por meio de nossas metáforas, buscando decifrar os sonhos com o filtro dos sonhos da lenda do xamanismo.

De acordo com Menezes (2015, p. 22-23) nossos sonhos são os “(...) naturais reorganizadores da esfera mental”, os quais por meio desse mecanismo natural nos mostram informações. Sonhos que esquecemos não apresentam propósito, visto que “(...) nosso corpo possui dispositivos de proteção perfeitos". Para isso, por meio de um dos mitos de criação do xamanismo e com nossos sonhos bons, que marcam e nos trazem lembranças, utilizaremos o símbolo do filtro dos sonhos, figura 2, para inspirar a criatividade, imaginação e ajudar a transformar e materializar os sonhos e objetivos. 


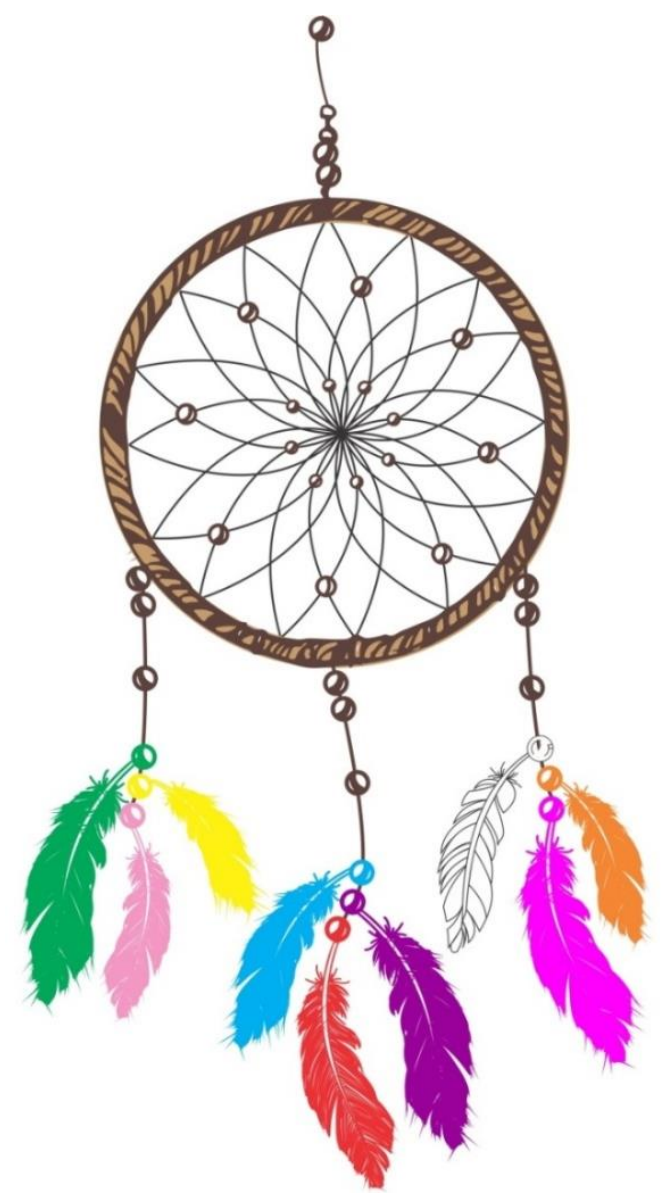

Figura 2: Cores que compõem o filtro dos sonhos

Fonte: Autores

O xamanismo é Terra, natureza, um movimento, é uma forma de religião que tem por finalidade auxiliar a resolução de questões do plano material. Essa ocorre por meio de “(...) curas físicas, mentais, emocionais e espirituais” envolvendo o contato com “(...) espíritos de seres humanos, de plantas, de animais, dos seres do mundo mineral e de elementais", estabelecendo trocas de energia através da sabedoria do comportamento das plantas e animais e dos elementos da terra, fogo, água e ar e dos elementais (MENEZES, 2014, p. 21-22).

A lenda do filtro dos sonhos conta que o xamã Sioux, índio de uma tribo norteamericana, na busca pela visão, pois os povos andavam às cegas, subiu no alto da montanha e encontrou Iktomi, um espírito mágico na forma de aranha. O espírito teceu uma teia com pelos de cavalo e oferendas recebidas em um círculo feito de cipó. Enquanto tecia disse ao xamã Sioux: "Se você trabalhar com forças boas, será guiado na direção certa e entrará em harmonia com a natureza. Do contrário, irá para direção que causará dor e infortúnios" (RUMI, 2016). Após tecer o filtro, o espírito mágico entregou-o ao xamã contando que o centro significa o ciclo da vida e que deveria ser usado para alcançar os objetivos, por meio 
das ideias, sonhos e visões, os quais vêm do Espírito do Mundo. A teia, ao se mover, consegue pegar sonhos, quando ainda estão no ar. Os sonhos bons sabem o caminho e deslizam suavemente pelas penas até alcançar quem está dormindo e os ruins ficam presos no círculo até o nascer do sol, desaparecendo na primeira luz do dia (RUMI, 2016).

Assim, inspirados nessa lenda conduzimos nossos sonhos, de sonharmos mais e tecermos um diálogo em conjunto com sujeitos que permeiam a pesquisa, pesquisadores e teóricos. Nesse sentido, nossa pesquisa tem caráter qualitativo, pois de acordo com Appolinário (2011) a realidade é constituída de fenômenos socialmente construídos, tendo como objetivo compreender os fenômenos associados a formação interdisciplinar de professores de Ciências. Nessa perspectiva essa pesquisa qualitativa é orientada pelos princípios do pensamento complexo que aspira por “(...) um saber não parcelado, não dividido, não reducionista e o reconhecimento do inacabado e incompleto de todo conhecimento" (MORIN, CIURANA e MOTTA, 2003, p.54).

Partimos da ideia de compreender, descrever, interpretar as informações emergentes, sendo que o "corpus" da pesquisa se constituirá pelas informações produzidas com instrumento de coleta de informações realizado. Com isso, a análise é organizada a partir de três momentos que fazem parte de um processo auto-organizado: a desmontagem dos textos ou unitarização, estabelecimentos de relações ou categorização e a produção de meta-textos. A partir dos princípios do pensamento complexo, vemos que a auto-organização contribui para percebermos as emergências que fazem parte desse processo recursivo. As emergências, produto da organização, apresentam-se como qualidades novas da unidade global (MORIN, 2016). Na ATD, no primeiro momento, fragmentamos nosso "corpus" em partes, a fim de aproximarmos mais do fenômeno investigado.

$\mathrm{Na}$ unitarização buscamos “(...) conseguir perceber os sentidos dos textos em diferentes limites pormenores, ainda que se saiba que um limite final e absoluto nunca é atingido" (MORAES e GALIAZZI, 2007, p. 18). Nesse processo, temos a desorganização das informações, de modo que ao desorganizá-las estabelecemos uma nova ordem, a partir das constrições iniciais e das interações com interlocutores teóricos e com as linguagens registradas pelos sujeitos do filtro dos sonhos. Assim, “(...) a ordem organizacional (turbilhão) pode nascer a partir de um processo que produz desordem (turbulência)" (MORIN, 2015a, p. 62).

Nesse movimento de desordem/ordem é necessário elaborar um sistema de códigos, de forma a possibilitar ao pesquisador a relação entre as unidades e a construção de categorias por meio do "corpus". As unidades de significado são fragmentos do "corpus", “(...) trabalho 
criativo de reconstrução de significados que os autores dos textos pretenderam expressar neles" (MORAES e GALIAZZI, 2007, p. 53). E os títulos são registros atribuídos pelo pesquisador, a partir das suas concepções teóricas e visão de mundo, um processo de cocriação de sentidos emergentes, frente às interlocuções com as ideias comunicadas pelos sujeitos de pesquisa, de forma a organizar, posteriormente, a categorização.

A categorização, processo de auto-organização, ocorre através da “(...) comparação constante entre as unidades definidas (...), levando ao agrupamento de elementos semelhantes. Conjuntos de elementos de significação próximos constituem as categorias" (MORAES e GALIAZZI, 2007, p. 22). Nesse instante, temos um olhar do todo por meio das partes, superando o reducionismo e holismo, pois todo e partes apresentam seus significados vinculados ao contexto.

O reducionismo busca uma unidade fundamental, a qual tem por finalidade simplificar a realidade do sistema. Sendo assim, “(...) ignora as transformações que ocorrem nas partes, ignora o todo enquanto todo, as qualidades emergentes (...), os antagonismos latentes" (MORIN, 2016, p. 156). No holismo temos como objetivo superar reducionismo, mas que ao reduzir o todo, retorna à simplificação.

Significamos que ambos, reducionismo e holismo, acabam por simplificar o complexo, e de certa forma essas visões se encontram dentro do paradigma simplificador. Nesse sentido, o paradigma complexo menciona que o todo é mais que o todo, assim como o todo é menos que o todo, pois “(...) visto isoladamente o todo não passa de um vazio (...)" (MORIN, 2016, p. 159). Registramos que ambas, as partes e o todo, dependem uma da outra para explicá-las, sendo assim um processo recursivo.

A interação com o "corpus" da pesquisa é recursivo, com idas e voltas, sendo que ao longo do mesmo, ocorre um aperfeiçoamento e clareza das categorias que se formam. A escrita é recursiva e criativa, de forma a constituirmos a realidade e novos argumentos, como ressaltam os referidos autores "quando isso é conseguido (...) a escrita produz novas realidades" (ibidem, p. 107). Dessa forma, temos as categorias iniciais que emergem dos significados e das compreensões, sendo evidenciados por meio dos títulos construídos a partir das unidades de significado. O processo de categorização é lento, longo e exigente, o fenômeno vai tomando forma “(...) de um modo sintético e ordenado", auto-organizando-se (MORAES e GALIAZZI, 2007, p. 77).

O movimento de emergir com "(...) esse tipo de categoria implica na organização de estruturas de vários níveis, indo o movimento das categorias mais específicas e de menor amplitude para as mais gerais e amplas" (MORAES e GALIAZZI, 2007, p. 88). No entanto, 
nesse momento da categorização as ligações entre as categorias emergentes e a teoria que orienta nosso estudo, o pensamento complexo, foram se manifestando. Os referidos autores ressaltam que “(...) o processo de categorização é diretamente influenciado pelas teorias analíticas e interpretativas que o pesquisador assume em suas pesquisas" (ibidem, p. 77).

As Categorias Finais, ainda que provisórias, são decorrentes desse processo de autoorganização, por meio das relações estabelecidas no processo de categorização. Essas categorias finais foram o ponto de partida para a escrita dos metatextos. Os metatextos são construções que se organizam a partir da “(...) descrição e interpretação, representando o conjunto um modo de teorização sobre os fenômenos investigados" (MORAES e GALIAZZI, 2007, p. 32). Esse é um processo recursivo organizacional, o qual "corpus”, pesquisador e teóricos se encontram, construindo e reconstruindo produções e procurando abranger distintos objetivos de análise. Desse modo, a Análise Textual Discursiva culmina com a produção de metatextos, processo em que emergem as compreensões,

(...) que se inicia com um movimento de desconstrução, em que os textos do "corpus" são fragmentados e desorganizados, seguindo-se um processo intuitivo auto-organizado de reconstrução, com emergência de novas compreensões que, então, necessitam ser comunicadas e validadas cada vez com maior clareza em forma de produções escritas. (MORAES e GALIAZZI, 2007, p. 41)

Neste procedimento é realizado o ciclo da ATD que descreve esse processo de análise, como mostramos na figura 3.

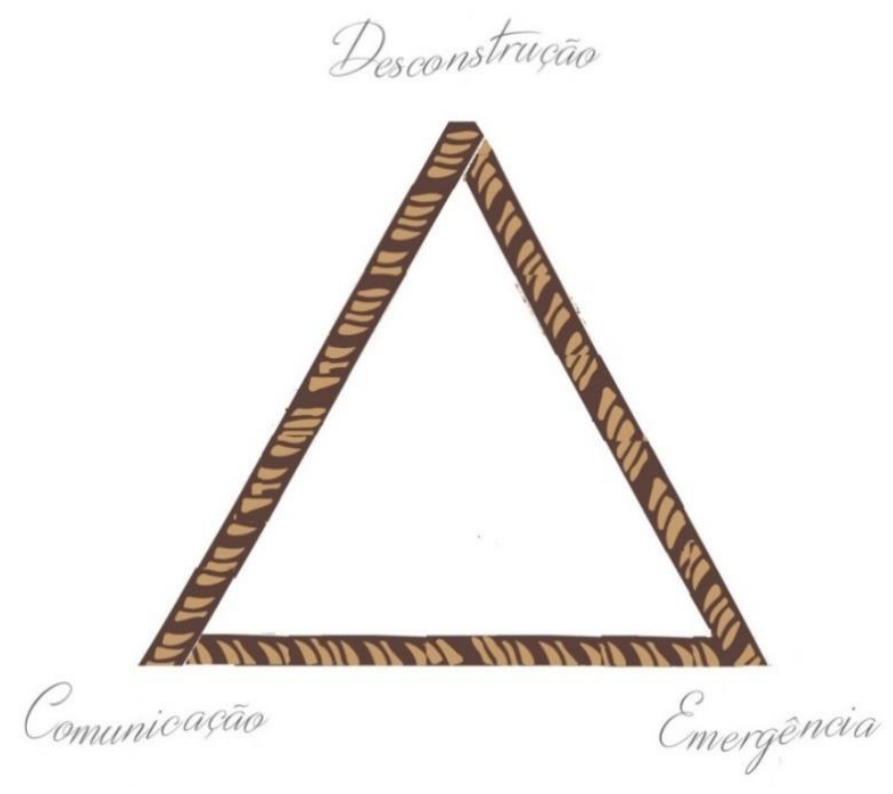

Figura 3: Ciclo da Análise Textual Discursiva adaptado Fonte: Moraes e Galiazzi (2007, p. 41) 
Percebemos uma proximidade com a ATD e o circuito tetralógico de Morin (2016, p. 78), figura 4, o qual explicita que as “(...) interações são inconcebíveis sem desordem, ou seja, sem desigualdades, turbulências, agitações, etc., que provocam os encontros”.

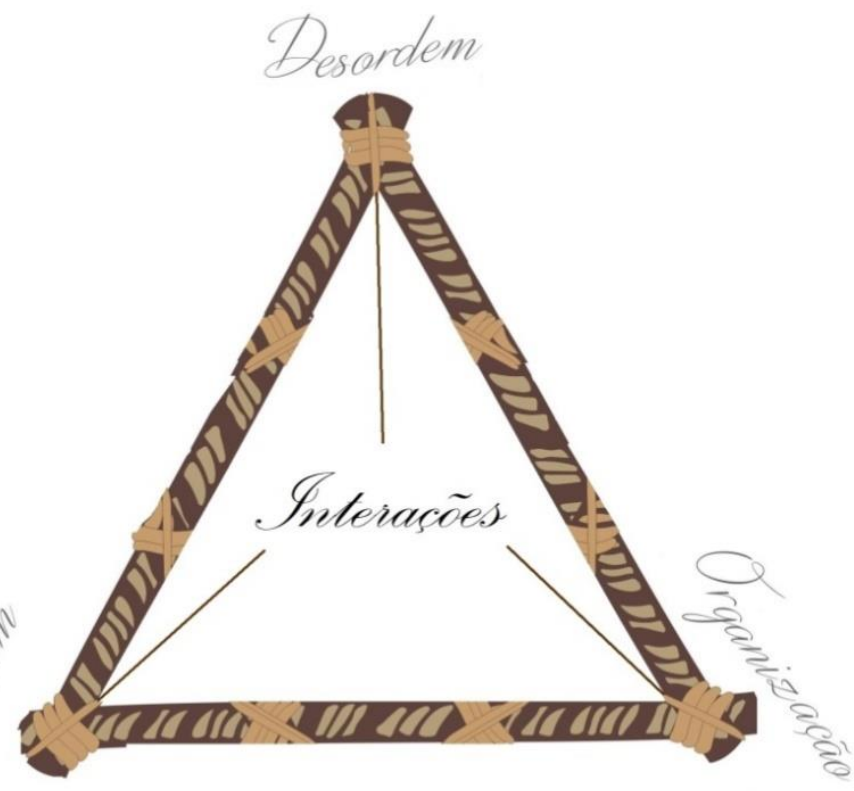

Figura 4: Circuito Tetralógico adaptado Fonte: Morin (2016, p. 78)

Por intermédio dessas relações que compreendemos para o percurso metodológico de nosso estudo a existência de uma associação entre o ciclo da ATD e o circuito tetralógico. Registramos na figura 5 uma adaptação de como ambos podem caminhar juntos, ATD e complexidade. 


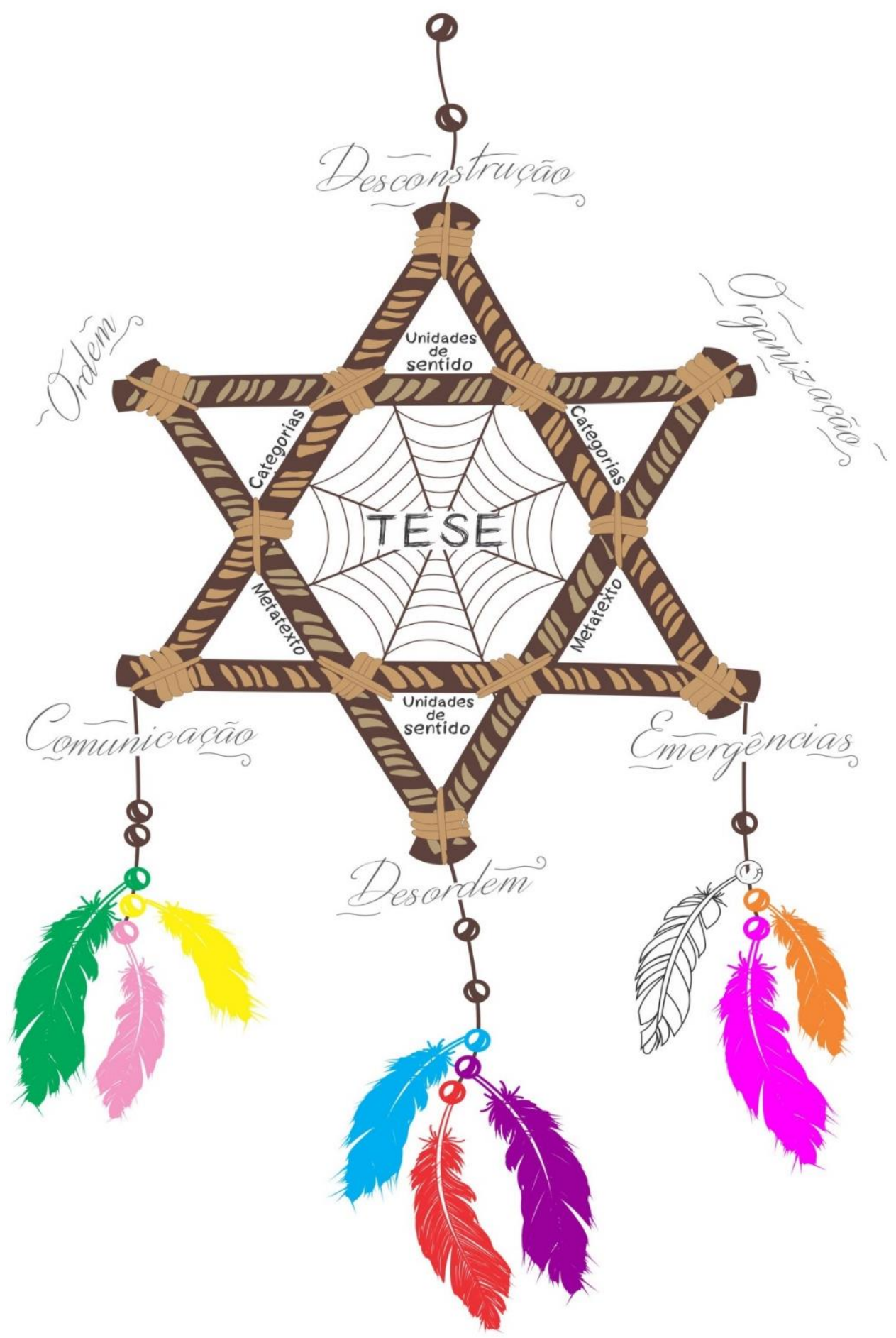

Figura 5: Adaptação do ciclo da ATD e circuito tetralógico no Filtro dos Sonhos

Fonte: os autores

Com a figura 5, ilustramos as conexões entre o pensamento complexo e a Análise Textual Discursiva. Compreendemos que as interações são essenciais nesse movimento de análise, pois os encontros desde o momento de produção das informações até a análise são produtores das emergências da tese, referentes a pesquisa realizada. Por isso, a trama que une os dois triângulos superpostos, ou seja, o ciclo da ATD e o circuito tetralógico da 
complexidade, também expressa a indissociabilidade entre os aspectos metodológicos e epistemológicos da pesquisa.

Além disso, nosso filtro dos sonhos, desconstruído, passa de um centro circular para uma estrela constituída por seis pontas. O círculo simboliza nosso relacionamento com o ecossistema, indicando o aspecto de extrema e integral integração da vida. Nossa estrela, nesse caso simbolizada pela estrela de $\operatorname{Davi}^{4}$ com a sobreposição dos triângulos, que representa como um dos significados o confronto entre o espírito e o físico. No entanto, para nosso filtro dos sonhos compreendemos como um momento de unirmos nosso pensamento mítico e pensamento racional.

Assim, com esse filtro dos sonhos transformado, em nosso primeiro movimento, temos a unitarização, com a desconstrução, a desordem. A desordem se torna necessária, visto que é desta que decorre a ordem. É das turbulências, agitações, desconstruções, que elaboramos possibilidade de ordem. Nessa etapa de desestruturação das ideias, produzimos relações entre os elementos unitários (MORAES e GALIAZZI, 2007), os quais são fragmentados e isolados nesse exercício racionalizado.

Ordem e organização se desenvolvem nesse processo posterior de interações, do qual emergem as categorias. Esse segundo movimento de reconstrução, de reorganização pode ser “(...) surpreendente e inesperado” (idem, p.45), “(...) processos necessariamente inseguros. $\mathrm{O}$ inesperado, as incertezas fazem parte da experiência do sujeito, visto que podemos considerar “(...) uma abertura para o desconhecido, para o que não se pode antecipar nem "pré-ver" nem "pré-dizer" (BONDÍA, 2002, p. 28, grifos do autor). Porém, Morin afirma que (2015c, p. 42) “(...) incertezas e dúvidas estão ligadas”, sendo assim são nesses momentos incertos que tomamos as decisões, aperfeiçoando o processo de organização e reconstrução.

A comunicação das novas compreensões ocorre por intermédio das emergências, produto da nossa organização, e assim como na escrita dos metatextos, o qual por meio de argumentos e “(...) “insights" atingidos são expressos em forma de linguagem e em profundidade e detalhes" (MORAES e GALIAZZI, 2007, p. 43, grifo do autor). Essas emergências fazem do princípio sistêmico ou organizacional, a qual ressalta que essas “(...) são efeitos organizacionais, produto (produzir: trazer ao ser) da disposição das partes no seio da unidade sistêmica”, sendo assim qualidades que ficam “(...) restringidas e inibidas por efeito da retroação organizacional do todo sobre as partes” (MORIN, 2003, p.33).

\footnotetext{
${ }^{4}$ Nossa estrela é considerada a Estrela de Davi. A diferença se dá na forma como os triângulos estão dispostos, um sobrepondo o outro, não ocorrendo o entrelaçamento de ambos.
} 
Registramos, que as conexões entre ATD e Pensamento Complexo estarão permeadas pela interação e pela linguagem expostas nos metatextos, por meio desse sistema caótico que se auto-organiza ao longo desse processo.

\section{Considerações Finais}

No estudo realizado explicitamos o caminho metodológico utilizado para investigar e compreender a formação inicial interdisciplinar em Ciências da Natureza. Possibilitou estabelecer uma articulação através da metáfora do sonho entre a metodologia de pesquisa da Análise Textual Discursiva de Roque Moraes e Maria do Carmo Galiazzi e os princípios epistemológicos do Pensamento Complexo de Edgar Morin.

Com a metáfora do sonho que permeia todo o trabalho, reconfiguramos o símbolo do filtro dos sonhos, que se transformou por meio dos princípios que o permeiam. Nessa nova representação percebemos relações entre o pensamento complexo e ATD, de modo que metodologia e epistemologia se relacionam por meio da metáfora. Em um primeiro movimento da análise tivemos a desconstrução e a desordem, através das unitarização, consequentemente ordem e organização se desenvolveram em um processo de interações, na qual emergem as categorias. E, com essas reorganizações e as emergências ocorrem novas compreensões que são expressas pela linguagem.

Significamos que no processo metodológico articulado ao contexto epistemológico, pesquisador(es) e textos são conjuntamente transformados em um processo que acontece com a escrita recursiva em um intenso movimento de análise. As interações com as linguagens do corpus do estudo precisa ser recursivo, como forma de possibilitar o aperfeiçoamento dos significados e ampliar as compreensões do(s) sujeito(s) envolvido(s). Ao escrever de forma crítica e criativa, constituímos diferentes realidades pela prática de estruturar argumentações, no emergir de unidades de sentido, na elaboração de títulos, categorias e na auto-organização dos metatextos. Importante ressaltar, que só é possível interconectar metodologia e epistemologia em um processo lento e recursivo.

Registramos que esse estudo é inicial sobre as relações entre a metodologia de análise e a epistemologia referenciadas. Nesse sentido, outras compreensões e relações entre as mesmas podem emergir de acordo com o prosseguimento do estudo e as aplicações em futuras pesquisas, assim como, as questões sobre a linguagem é um dos pontos a serem inseridos dentro das relações entre ATD e pensamento complexo. 


\section{Referências}

APPOLINÁRIO, F. Metodologia da Ciência: filosofia e prática da pesquisa. São Paulo: Cengage Learning, 2011.

ARAÚJO, R. R de. Entre sonhos e realidades: A auto-eco-formação interdisciplinar de professores em Ciências da Natureza. 2017. 155 f. Tese (Doutorado em Educação em Ciências) - Programa de Pós-Graduação em Educação em Ciências, Universidade Federal do Rio Grande - FURG. 2017.

BARDIN, L. Análise de Conteúdo. São Paulo: Edições 70, 2011.

BICUDO, M. A. V. Aspectos de pesquisa qualitativa efetuada em uma abordagem fenomenológica. In: BICUDO, M. A. V. Pesquisa Qualitativa: segundo a visão fenomenológica. São Paulo: Cortez, 2011.

BICUDO, M. A. V.; KLÜBER, T. E. A questão de pesquisa sob a perspectiva da atitude fenomenológica de investigação. Conjectura: Filosofia e Educação, v. 18, n. 3, p. 24-40, set./dez. 2013.

BONDÍA, J. L. Notas sobre a experiência e o saber de experiência. Revista Brasileira de Educação, n. 19, p. 20-28, jan/abr, 2002.

CARVAlHO, R. F. Temporalidade e Historicidade em Ilya Prigogine. 2012. 160 f. Dissertação (Mestrado em História) - Faculdade de História, Programa de Pós-Graduação em História, Universidade Federal de Goiás. 2012.

JUNG, C. G. O homem e seus símbolos. 2 ed. especial. Rio de Janeiro: Nova Fronteira, 2008.

MENEZES, J. O poder das histórias contadas no xamanismo de Jorge Menezes. Porto Alegre: Hapha, 2015.

MENEZES, J. A força da calma no xamanismo de Jorge Menezes. Porto Alegre: Hapha, 2014.

MORAES, R.; GALIAZZI, M. C. Análise Textual Discursiva. Ijuí: Editora UNIJUÍ: 2007.

MORAES, M. C.; LA TORRE, S. de. Pesquisando a partir do pensamento complexo elementos para uma metodologia de desenvolvimento eco-sistêmico. Educação, n. 1, v. 58, p. 145-172, jan./abr. 2006.

MORIN, E. O método 1: a natureza da natureza. 3 ed. Porto Alegre: Sulina, 2016.

MORIN, E. O método 3: o conhecimento do conhecimento. 5 ed. Porto Alegre: Sulina, 2015 a.

MORIN, E. Introdução ao pensamento complexo. 5 ed. Porto Alegre: Sulina, 2015b.

MORIN, E. $O$ método 2: a vida da vida. 5 ed. Porto Alegre: Sulina, 2015c. 
MORIN, E. Ciência com consciência. 16º ed. Rio de Janeiro: Bertrand Brasil, 2014.

MORIN, E. O método 5: a humanidade da humanidade. 5 ed. Porto Alegre: Sulina, 2012.

MORIN, E. A cabeça bem-feita: repensar a reforma, reformar o pensamento. 8 ed. Rio de Janeiro: Bertrand Brasil, 2003.

MORIN, E.; CIRUANA, E. R.; MOTTA, R. D. Educar na era planetária: O pensamento complexo como Método de aprendizagem no erro e na incerteza humana. São Paulo: Cortez, 2003.

PESSOA, F. de. Livro do Desassossego. Disponível em: <https://www.luso-livros.net/wpcontent/uploads/2013/11/Livro-do-Desassossego-.pdf>. 2013. Acesso em: 10 de jan. 2017.

PRIGOGINE, I. O fim da certeza. In: MENDES, C. (org). Representação e complexidade. Rio de Janeiro: Garamond, 2003.

PRIGOGINE, I. O fim das certezas: tempo, caos e as leis da natureza. São Paulo: Editora da Universidade Estadual Paulista, 1996.

RUMI, A. Origem do filtro dos sonhos, 2016. Disponível em: <http://www.xamanismo.com.br/filtro-dos-sonhos/>. Acesso em 10 de fev. 2017.

SCHMIDT, L. K. Hermenêutica. 3 ed. Petrópolis: Vozes, 2014.

VASCONCELLOS, M. J. E. de. Pensamento sistêmico: o novo paradigma da ciência. $10^{\mathrm{a}}$ ed. Campinas: Papirus, 2013. 